\title{
Workplace Bullying and its effect on Staff Nurses' Work Engagement
}

\author{
Amira Ali Mohammed Attia: B.Sc. N- Faculty of Nursing -Tanta University \\ Reda Abd El-Fatah Abo Gad: Assist. Prof. of Nursing Services Administration, Faculty of nursing, \\ Tanta University
}

Maha Eid Shokir: Lecturer of Nursing Services Administration, Faculty of nursing, Tanta University

\begin{abstract}
:
Back ground: Workplace bullying is a social and organizational problem within the health care, it has several adverse effects and closely associated with nurses' work engagement. Aim: The study aimed to assess the effect of workplace bullying on nurses' work engagement. Research Design: Descriptive correlational research design was used in the study. Setting: the study was conducted at EL-Menshawy Hospital, which affiliated to the Ministry of Health and Population. The study subjects: Consisted of a represented sample of staff nurses $(\mathrm{n}=$ 250). Tools: Data was collected by using two tools. 1) workplace bullying questionnaire; 2) nurses' work engagement questionnaire. Results: The result showed that majority of staff nurses had high level of bullying and more than two-fifths of the staff nurses had low level of work engagement. Conclusion: There was statistically significant correlation between nurses' bullying and their engagement. Recommendation: As bullying seems to be a serious problem among staff nurses at EL-Menshawy Hospital, Nurses at all levels, Nursing administrators need to develop policies to prevent bullying and setting up mechanisms that allow nurses who exposed to workplace bullying to report incidents of bullying.
\end{abstract}

Key words: engaged nurses', workplace bullying, work engagement. 


\section{Tanta Scientific Nursing Journal}

\section{Introduction}

Nursing is the cornerstone of health care system that is currently attack by challenges, problems and opportunities. Twenty-four hours a day, seven days a week, whether in community health centers, hospitals or isolated nursing stations, nurses are often the first when there is a need of care ${ }^{(1)}$. To ensure quality and to promote a culture of safety, health care organizations must address the problem of behaviors that threaten the performance of the health care team ${ }^{(2)}$. Workplace bullying violates the ethical principle that is paramount to nursing respect the worth, dignity and human rights of all individuals including colleagues. Hence, nurses are entitled to work in an environment that is free from bullying, harassment and threatening behaviors ${ }^{(3)}$.

Negative workplace behavior such as bullying is a worldwide problem ${ }^{(4)}$. Workplace bullying is a complex phenomenon that can only be understood through looking at social, individual and organizational factors pointed out that the issue of workplace violence and bullying is something of which all organizations must be aware as it affects staff and in the case of nurses, it can also affect patients ${ }^{(5)}$.
Bullying is behavior which generally persistent, systematic and ongoing" (6). Bullying in the nursing workplace is a subset of workplace bullying, which existed in nursing for an extended period. Workplace bullying is repeated inappropriate behavior, direct or indirect, whether verbal, physical or otherwise, conducted by one or more persons against another or others, at the place of work, which could reasonably be regarded as undermining the staff nurses right to dignity at work ${ }^{(7)}$.

Bullying refers to the relentless occurrence of negative acts and hostile behaviors aimed towards nurses. Bullying acts are comprised of several categories of bullying including personal attacks, erosion of professional competence and reputation, and attack through work roles and tasks. Personal attacks are bullying acts that characterize a nurse's experience of feeling ignored, insulted, blamed, and put down ${ }^{(8)}$. The erosion of professional competence and reputation is a bullying act characterized by public humiliation, downgrading of skills and abilities, and tactics to undermine career advancement of the individual. Attack through work roles and tasks is a bullying act that is 


\section{Tanta Scientific Nursing Journal}

characterized by unfair work assignments, sabotage, withholding of information, denial of due process and use of earned benefits, and unfair economic restrictions $^{(9)}$.

Bullying has adverse consequences for the target. A target of bullying has lowers self-esteem and produce psychological problems such as fear, anxiety, helplessness, depression and posttraumatic stress disorder. Workplace bullying has also widespread negative effects on the organization as a whole. Which produce less organizational citizenship, reduces satisfaction and commitment, decreases productivity, decrease engagement, propensity to leave and turnover ${ }^{(10)}$. The interaction between staff nurses and their work environment determine their behavior. In accordance with this, the congruity of nurses and organizational values may encourage positive behavior in a work and organizational context. Thus, nurses may be willing to put in high levels of energy and be strongly involved in their work ${ }^{(11)}$. Engaged staff nurses are energized, dedicated, and motivated to persevere and complete their work. They enjoy challenges, exhibit mental resilience, and are engrossed in their work (12).
Engagement is a predictor of nurses' proactive behaviors, loyalty and performance, and financial returns. Further, more engagement contributes to a variety of benefits for both the staff nurses and the organizations in which they work $^{(13)}$.

Engagement has been defined as a persistent, pervasive and positive affective motivational state of fulfillment in professionals ${ }^{(14)}$. Work engagement is defined as a positive, fulfilling, workrelated state of mind that is characterized by vigor, dedication and absorption. Vigor is characterized by high level of energy and mental resilience while working. Dedication refers to being strongly involved in one's work and experiencing a sense of significance and proud. Finally, absorption is characterized by being fully concentrated and happy engrossed in one's work" ${ }^{(14)}$.

Work engagement concept involves a personal commitment to reaching goals, and engaged nurses put a personal energy and enthusiasm into their work. The focus and energy that is characteristic of work engagement allow nurses to bring their full potential into the work (15). Work engagement is a very good predictor of important nurses, team, and organizational 
outcomes. Because of their strong dedication to and focus on their work activities, engaged nurses show better inrole task performance and better financial results. Moreover, because of their openness to new experiences, engaged nurses have more creative ideas and are more likely to innovate and be entrepreneurial $^{(16)}$.

\section{Significant of the study}

Workplace bullying serves as an impediment or barrier to staff nurses work engagement. Therefore, workplace bullying is associated with low levels of work engagement ${ }^{(17)}$. So, with increasing the need to attract and retain engaged nurses, in recent years there has been need to focus on understanding factors that affect the well-being of nurses and their work behaviors such as engagement. One of the most important factors is workplace bullying ${ }^{(18)}$. So, this study was conducted to explore the effects of the workplace bullying on work engagement among staff nurses at El-Menshawy Hospital, hoping that findings of this study will help decision makers to plan for redesigning the work in such a way to minimize workplace bullying and its related consequence

\section{Aim of the Study:}

The aim of this study is to: Assess the workplace bullying and its effect on staff nurses' work engagement.

Research question

1.What are levels of staff nurses' perceived workplace bullying?

2.What are levels of staff nurses' work engagement?

3.What are the effects of the workplace bullying on staff nurses' work engagement?

\section{Subjects and Methods}

\section{Research Design}

A descriptive correlational study design was used to achieve the aim of the study.

\section{Setting:}

The study was conducted at all departments of EL-Menshawy General Hospital, which affiliated to the Ministry of Health and Population

\section{Subjects:}

The study subject was included a representative random sample from total (680) nurses' size. The subject was calculated to be 250 staff nurses at $95 \%$ confidence level and purposive $90 \%$ power of the study who working at previous mentioned setting at the time of data 


\section{Tanta Scientific Nursing Journal}

collection and willing to participate in the study. The equation used is:

$$
[\mathrm{u} \vee \mathrm{p} 1(1-\mathrm{p} 1)+\mathrm{v} \sqrt{ } \mathrm{p} 0(1-\mathrm{p} 0)]^{2}
$$

• N------------------------------------ >

- $(\mathrm{p} 1-\mathrm{p} 0)^{2}$

- $\mathrm{U}=1.28, \mathrm{v}=1.96$

\section{Tools of data collection:}

To achieve the aim of this study, the following tools were used;

\section{Tool (I): Workplace bullying structured questionnaire}

It included two parts:

Part (I): Personal characteristics data of staff nurses' namely; age, sex, marital status, years of experience, work department, level of education, and previous attending training courses.

Part (II): Staff nurses' perceived workplace bullying. It was developed by El-sayed, (2015) ${ }^{(117)}$, Hutchinson, (2008) (118) and modified by investigator based on related literature ${ }^{(42,61,66)}$ to asses workplace bullying among staff nurses. It contained 114 items divided into five domains as follow;

1- Delineation of the bully (10 items).

2- Types of bullying included 35 items divided into five subscales.

- Professional threat (7 items).

- Personal threat (13 items).

- Work isolation (4 items).
- Work overload( 4 items).

- Work instability (7 items).

3- Organizational process toward workplace bullying (26 items).

4- Reporting of bullying (17 items).

5- Consequences of bullying included 25 items divided into two subscales.

- Job consequences (15 items).

- Bullying health problem (11 items).

\section{Scoring system:}

Staff nurses' responses for delineation of bully items was allotted a score of 1 for "yes" and 0 for "no". The workplace bullying five subscales was measured on a five-points Likert Scale ranging from (1) never, (2) rarely, (3) sometimes, (4) usually, and (5) always which concluded into three points namely never, sometimes and always. The total score were statistically calculated by summing scores of all categories where:

- High level of staff nurses' experience workplace bullying $\geq 75 \%$

- Moderate level of staff nurses' experience workplace bullying 60$<75 \%$

- Low level of staff nurses' experience workplace bullying $<60 \%$

Organizational system toward workplace bullying was measured on a five-points Likert Scale ranging from (1) strongly 
disagree, (2) disagree, (3) not sure, (4) agree and (5) strongly agree which concluded into three scores namely agree, not sure and disagree. The total score were calculated by summing scores of all categories where:

- High level of staff nurses' perception regarding organizational process $\geq 75 \%$

- Moderate level of staff nurses' perception regarding organizational process $60-<75 \%$

- Low level of staff nurses' perception regarding organizational process $<60 \%$ Response to report and consequences of bullying items were measured by one for "yes", zero for "no".

\section{Tool (II): Utrecht work engagement}

\section{questionnaire}

This tool was modified by researcher based on Utrecht work engagement questionnaire by Schaufeli, (2012) (119) This tool was used to measure staff nurses' perception regarding work engagement. It consisted of 17 items divided into 3 subscales as follow;

1. Vigor included first 6 items.

2. Dedication included 5 items.

3. Absorption included 6 items.

Scoring system:

Staff nurses' responses for work engagement were measured on a five- points Likert Scale ranging from 5 to 1 , where score (5) refers to Always, Score (4) refers to usually, Score (3) refers to sometimes, Score (2) refers to rarely, and Score (1) refers to never and were concluded into three points namely never, sometimes and always. The total scores were statistically calculated by summing scores of all categories and converted into percent score to assess the level of staff nurses' work engagement as follows:-

- High level of staff nurses' work engagement $\geq 75 \%$.

- Moderate level of staff nurses' work engagement $60-<75 \%$

- Low level of staff nurses' work engagement $<60 \%$.

\section{Method:}

1- Official permission was obtained from the director of Elmenshawy General Hospital to obtain the approval and assistance of general supervisor to collect the data.

\section{2- Ethical and legal consideration:}

- Approval of ethical committee at faculty of nursing was obtained

- The researcher introduced herself to the participant, staff nurses' informed consent for participation was obtained after explanation of the nature and the purpose of the study, confidentiality of 


\section{Tanta Scientific Nursing Journal}

the information obtained from them and the right to withdrawal was kept.

- The right to terminate participation at any time will be accepted.

3- The study tools were modified by the researcher based on review of the related literatures.

4- The tools were translated into Arabic and reviewed by the supervisors and submitted to seven experts to check content validity and clarity of questionnaire. The experts were; one assistant professor of Nursing Administration and two lecturers of Nursing Administration. Also, two assistant professor of Psychiatric Mental Health Nursing and two assistant professor of Community Health Nursing, Faculty of Nursing, Tanta University.

- The experts' responses were represented in four points rating scale (4-1) ranging from $4=$ strongly relevant, $3=$ relevant, $2=$ little relevant, and $1=$ no relevant. Necessary modification were done including; clarification, omission of certain items and simplifying work related words and collecting subcategories of types of workplace bullying to one domain and adding organizational processes regarding bullying in workplace, reporting of bullying and consequences of bullying domains.

- The face validity value of tool (1): Workplace bullying types $=93.6 \%$. Tool (2) Nurses' work engagement= $95.47 \%$.

5- A pilot study was carried out on a sample of $10 \%$ of the subject $(n=25)$ and they excluded from the main study sample during the actual collection of data. A pilot study was carried out after the experts' opinion and before starting the actual data collection. The pilot study was done to test clarity, sequence of items, applicability, relevance of the question, and to determine the needed time to complete the questionnaire. According feedback from pilot study, the tool was modified by the researcher. The estimated time needed to complete the questionnaire items from nursing staff was 20-30 minutes.

6- Reliability of tools was tested using Cronbach Alpha Coefficient test. Reliability of tool (I) Workplace bullying types was 0.956. and reliability of tool (II) Nurses' work engagement was 0.876 . 


\section{Tanta Scientific Nursing Journal}

7- Workplace bullying structured questionnaire and Utrecht work engagement scales was used to collected data from the identified subject.

8- Data collection phase: The data were collected from staff nurses by the researcher. The researcher met the respondents' nurses in small groups at their work settings and distributed the questionnaire. The subjects recorded the answers in the presence of the researcher to clarify and ascertain all questions were answered. The data was collected over period of three months started from January until March, 2019.

\section{Statistical analysis}

The collected data were organized, tabulated and statistically analyzed using IBM SPSS software package version 20.0. (Armonk, NY: IBM Corp). Qualitative data were described using number and percent. Quantitative data were described using range (minimum and maximum), mean, standard deviation. Significance of the obtained results was judged at the 5\% level. The used tests were 1) Student t-test for normally distributed quantitative variables, to compare between two studied groups; 2) F-test (ANOVA) for normally distributed quantitative variables, to compare between more than two groups; 3) Pearson coefficient to correlate between two normally distributed quantitative variables; 4) Cronbach's Alpha, reliability Statistics was assessed using Cronbach's Alpha test.

\section{Results}

Table (1): shows distribution of the nurses according to their personal characteristics. Staff nurses age were ranged between 22 to 55 years old with mean score age $30.02 \pm$ 6.70 and nearly two-thirds (62.8\%) of them were less than 30 years old. Regarding the years of experience, the years of experience ranged between 1-36 years with mean score9.18 \pm 7.35 and more than twofifths (43.2\%) staff nurses had less than 5 years of experience. Majority (89.2\%, $88.0 \%$ ) of staff nurses were females and married, respectively.

Figure (1): shows that more than half $(60.4 \%)$ of staff nurses were exposed to bullying in their work.

Figure (2): shows that around one-third $(34.0 \%, 30.0 \%)$ of staff nurses were reported that the source of their bullying was head nurse, and patient relatives, respectively. Equal percent (11.2\%) of them were reported that the source of their bullying were physician and colleague. 


\section{Tanta Scientific Nursing Journal}

Figure (3) shows that majority of staff nurses had high level of overall workplace bullying types. While, minority of staff nurses reported that they had low level of overall workplace bullying types.

Figure (4): shows that majority of staff nurses had high level of overall professional threats. While, minority of staff nurses reported that they had low level of overall professional threats.

Figure (5): As evident from figure, majority of staff nurses had high level of overall personal threat. While, minority of them had low level of overall personal threat.

Figure (6): Show that nearly three-quarters of staff nurses had high level of overall work isolation. While, minority of them had low level of overall work isolation.

Figure (7): shows that more than half of staff nurses had high level of overall work overload. While, minor percentage of them had low level of overall work overload.

Figure (8): shows that majority of staff nurses had high level of overall work instability, while minority of them had moderate level of overall work instability.

Figure (9): shows that three-quarter of staff nurses had low agreement level regarding overall organizational processes.
While, minority of them reported high agreement level.

Table (2): shows distribution of the staff nurses' opinion regarding to reporting of bullying. More than half $(53.6 \%, 52.8 \%)$ of staff nurses reported that they had an experience of bullying and saw bullying, respectively. More than two-fifths $(42.8 \%$, and $41.6 \%$ ) of staff nurses rationalized non reporting bully exposure as their decided to move position instead, feared reprisal, and would have affected their career, respectively.

Table (3): shows distribution of staff nurses' opinion regarding to job consequences as a type of workplace bullying consequences. Majority (84.0\%, and $80.4 \%$ ) of staff nurses reported that they response to reporting bullying were they applied for worker compensation, and used their sick leave to cope, respectively. Around three-quarters $(79.6 \%, 79.6 \%$, $78.0 \%, 76.0 \%, 74.4 \%$, and $73.2 \%$ ) of staff nurses reported that they response to reporting bullying were they had reduced their hours of work, moved positions within the organization, they had been overlooked for promotion, no longer working in their chosen field, were told that were weak and not coping, and were 


\section{Tanta Scientific Nursing Journal}

moved, not the bully, respectively.

Table (4): Presents distribution of staff nurses' opinion according to bullying health problems as a type of workplace consequences. Over three-quarters $(75.2 \%)$ of bullied nurses' complained from fatigue and exhaustion, while, more than twothirds (67.2\%) complained from headaches. Also, more than half $(60.8 \%$, $55.2 \%$, and $52.8 \%$ ) of them complained of sleeplessness, anxiety, and depression, respectively. More than two-fifths $(46.4 \%$, $45.2 \%$, and $42.4 \%$ ) of staff nurses complained of hypertension, memory loss, and gastric upset, respectively.

Figure (10): shows that more than twofifths of staff nurses had low level of overall work engagement characteristics. While, more than one-quarter of them had high or moderate level regarding overall work engagement characteristics.

Figure (11): represents that statistically negative significant correlation was found between staff nurses' overall workplace bullying and their work engagement ( $r=-$ 0.368 and $\mathrm{p}=<0.001)$. 


\section{Tanta Scientific Nursing Journal}

Table (1): Distribution of the nurses according to their personal characteristics data

\begin{tabular}{|c|c|c|}
\hline Variables & No. & $\%$ \\
\hline Age (years) & & \\
\hline$-\quad \leq 30$ & 157 & 62.8 \\
\hline$-\quad>30$ & 93 & 37.2 \\
\hline $\begin{array}{ll}- & \text { Min. - Max. }\end{array}$ & \multirow{3}{*}{\multicolumn{2}{|c|}{$\begin{array}{c}22.0-55.0 \\
30.02 \pm 6.70 \\
22-55\end{array}$}} \\
\hline - $\quad$ Mean \pm SD. & & \\
\hline - $\quad$ Rang & & \\
\hline Years of experience & \multirow{4}{*}{$\begin{array}{l}10 \\
70 \\
72\end{array}$} & \\
\hline$-\quad \leq 5$ & & \\
\hline$-5-10$ & & 28.0 \\
\hline$-\quad>10$ & & 28.8 \\
\hline - $\quad$ Min. - Max. & \multirow{3}{*}{\multicolumn{2}{|c|}{$\begin{array}{c}1.0-36.0 \\
9.18 \pm 7.35 \\
1-36\end{array}$}} \\
\hline$-\quad$ Mean \pm SD. & & \\
\hline - Rang & & \\
\hline Sex & & \\
\hline - Male & 27 & 10.8 \\
\hline - Female & 223 & 89.2 \\
\hline Educational level & & \\
\hline - Diploma & 70 & 28.0 \\
\hline - Technical Institute of nursing & 89 & 35.6 \\
\hline$-\quad \mathrm{BSN}$ & 87 & 34.8 \\
\hline - $\quad$ Others & 4 & 1.6 \\
\hline Marital status & & \\
\hline - $\quad$ Married & 220 & 88.0 \\
\hline - Single & 22 & 8.8 \\
\hline - $\quad$ Divorced & 4 & 1.6 \\
\hline - Widow & 4 & 1.6 \\
\hline Department & & \\
\hline - Medical & 95 & 38.0 \\
\hline - $\quad$ Surgical & 60 & 24.0 \\
\hline$-\quad$ ICU & 73 & 29.2 \\
\hline - Outpatient & 22 & 8.8 \\
\hline Previous attending training courses & & \\
\hline $\begin{array}{ll}- & \text { Yes } \\
- & \text { No }\end{array}$ & 87 & 34.8 \\
\hline $\begin{array}{l}\text { No } \\
\text { Type of attending training courses }\end{array}$ & 163 & 65.2 \\
\hline - $\quad$ training course related to ICU & 42 & 16.8 \\
\hline - Emergency training course & 25 & 10.0 \\
\hline- & 20 & 8.0 \\
\hline - Neonate training course & & \\
\hline
\end{tabular}




\section{Tanta Scientific Nursing Journal}

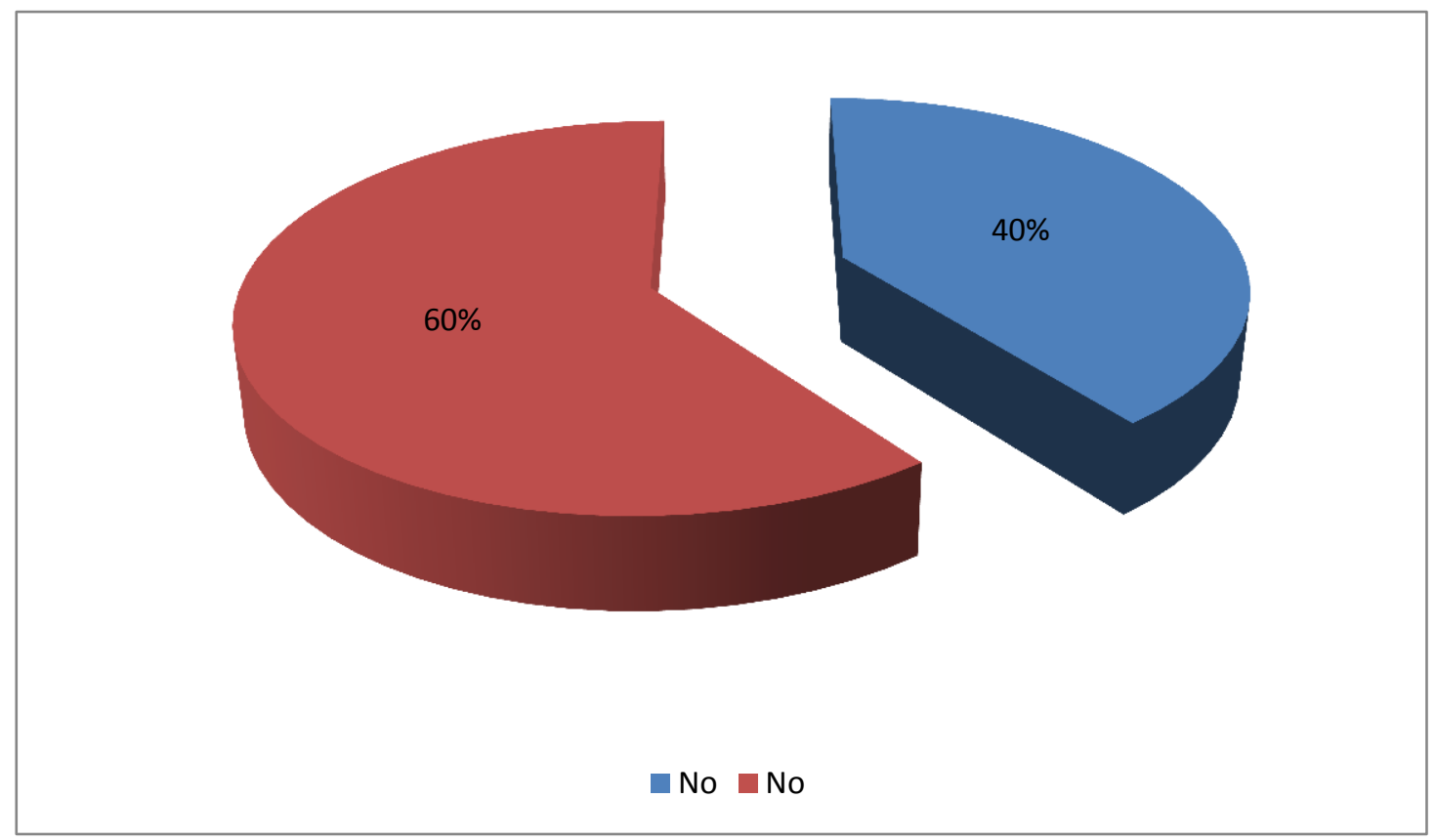

Figure (1): Distribution of the staff nurses' perception according to bully's definition

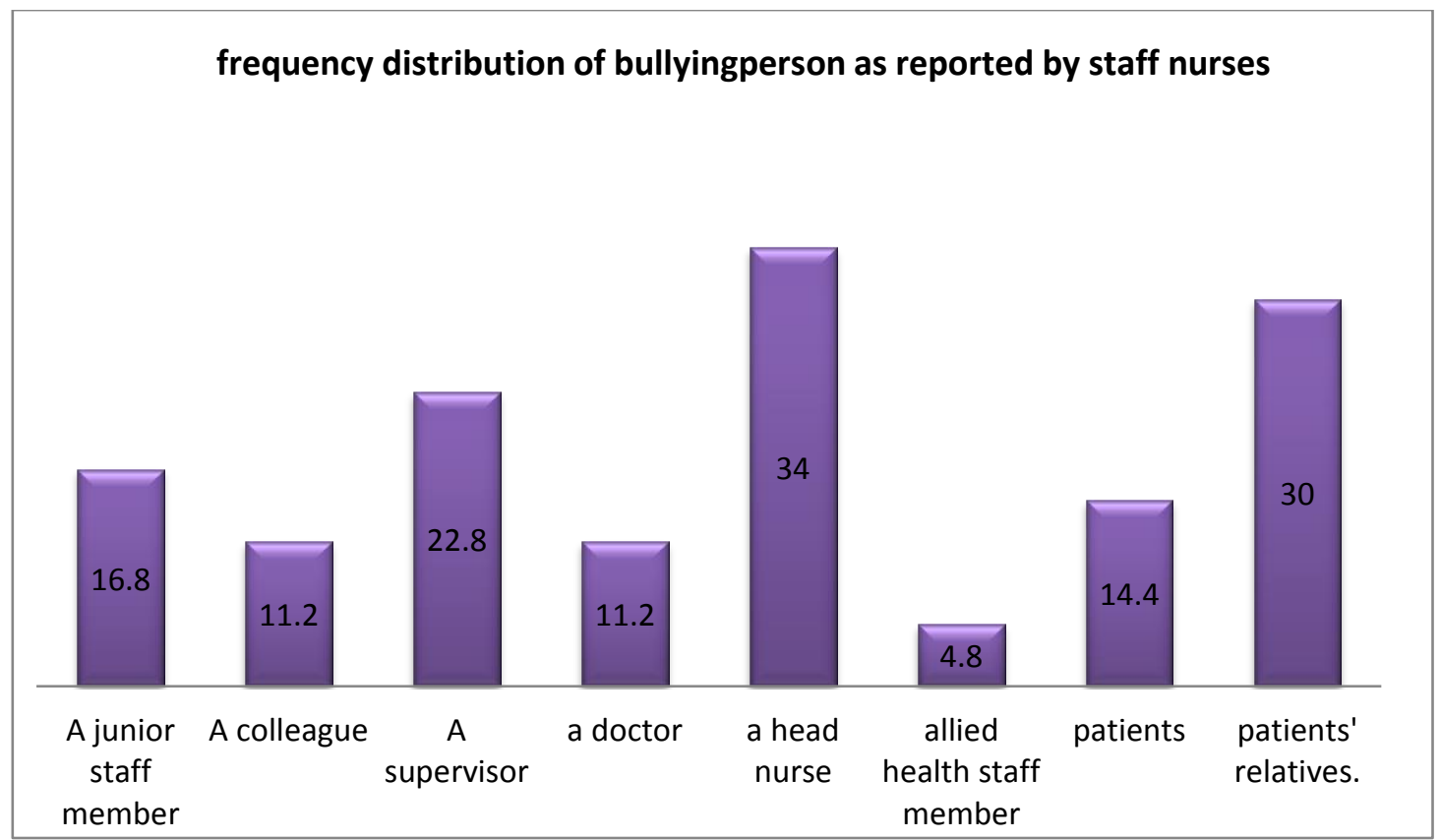

Figure (2): Frequency distribution of bullying person as reported by staff nurses 


\section{Tanta Scientific Nursing Journal}

staff nurses perception according to overall workplace bullying types

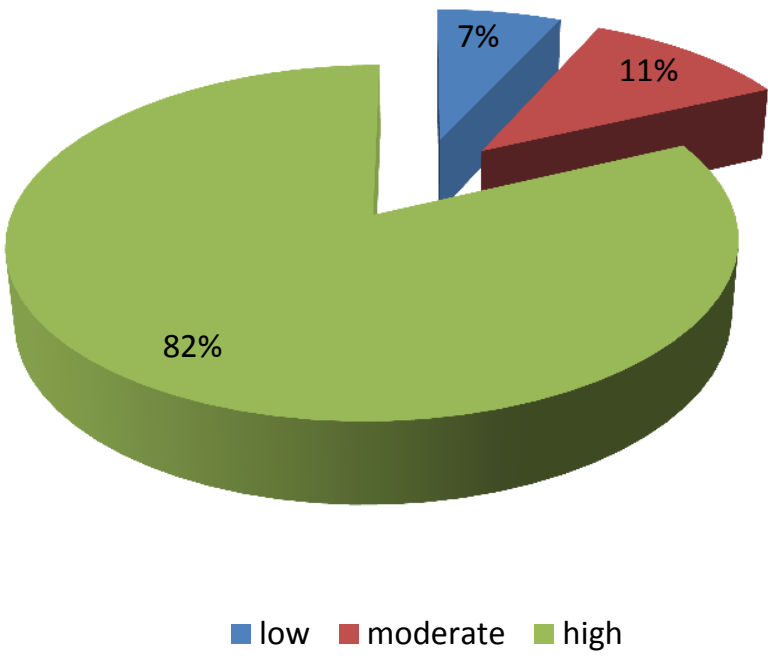

Figure (3): Levels of staff nurses according to overall workplace bullying types

Staff nurses' preception according to overall professional threats

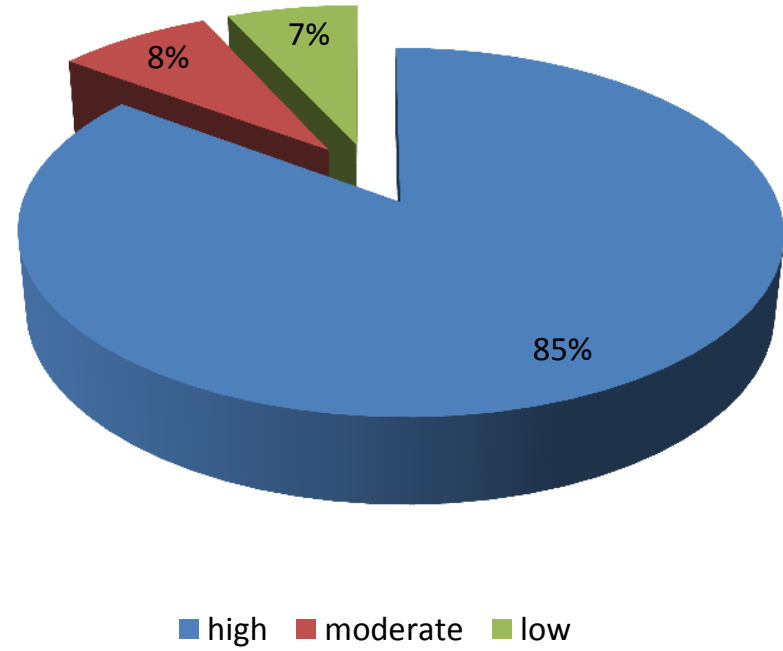

Figure (4): Levels of staff nurses according to overall professional threats 


\section{Tanta Scientific Nursing Journal}

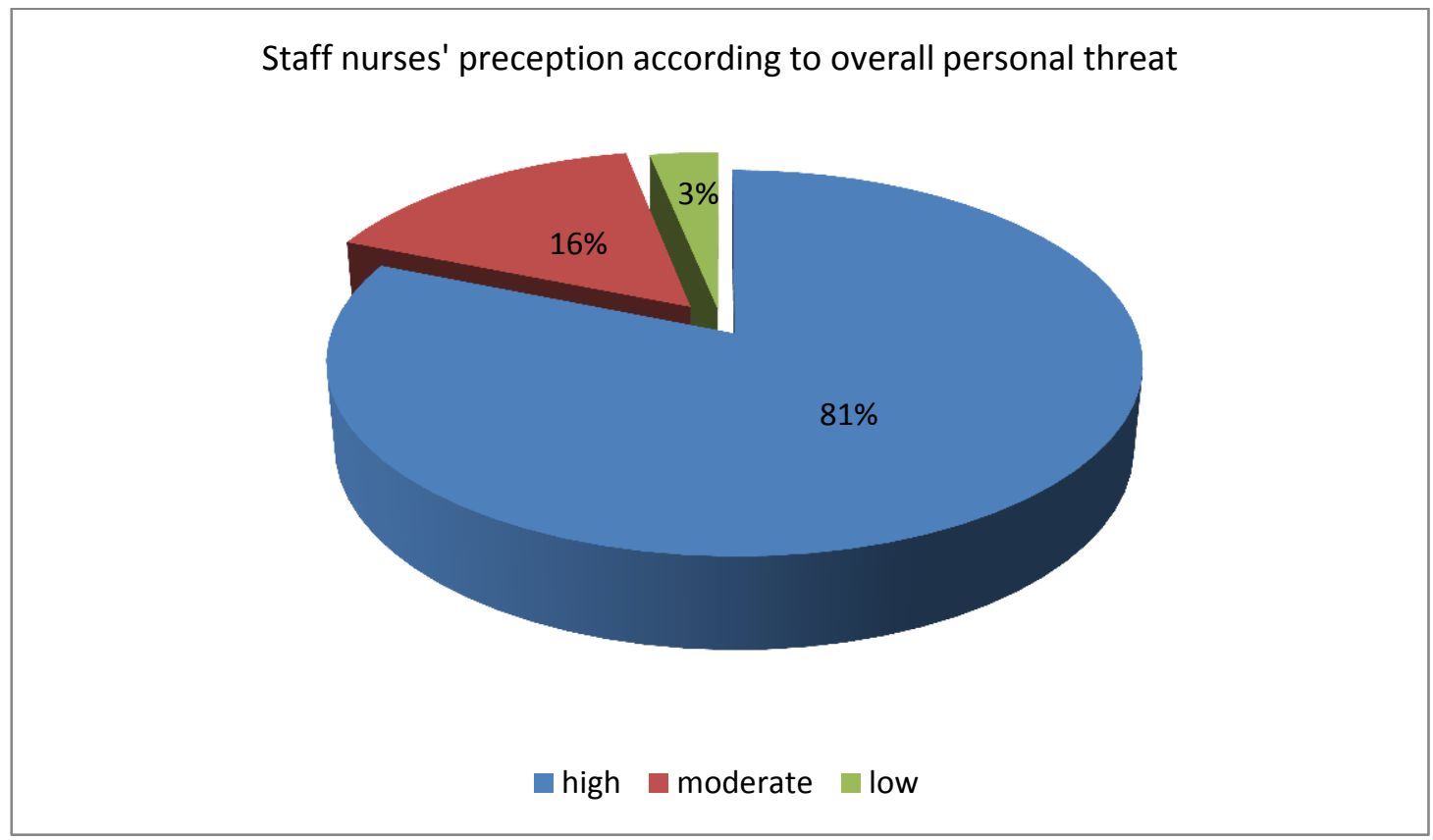

Figure (5): Levels of staff nurses according to personal threat

staff nurses' perception according to overall work isolation

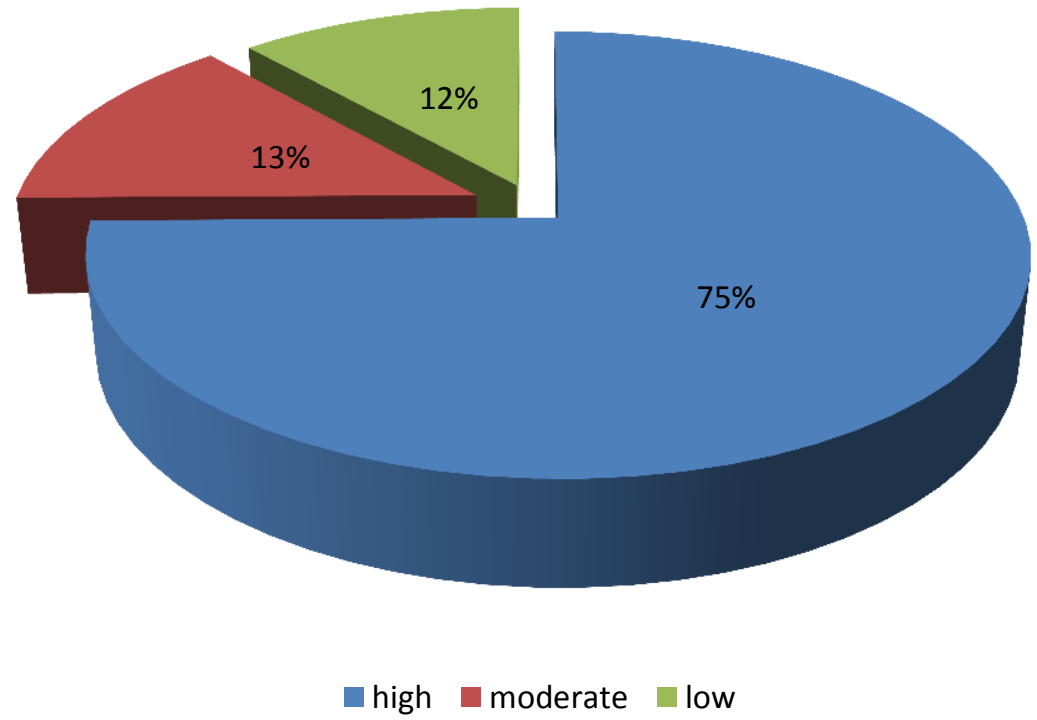

Figure (6): Levels of staff nurses according to overall work isolation 


\section{Tanta Scientific Nursing Journal}

Staff nurses' perception according to overall work overload

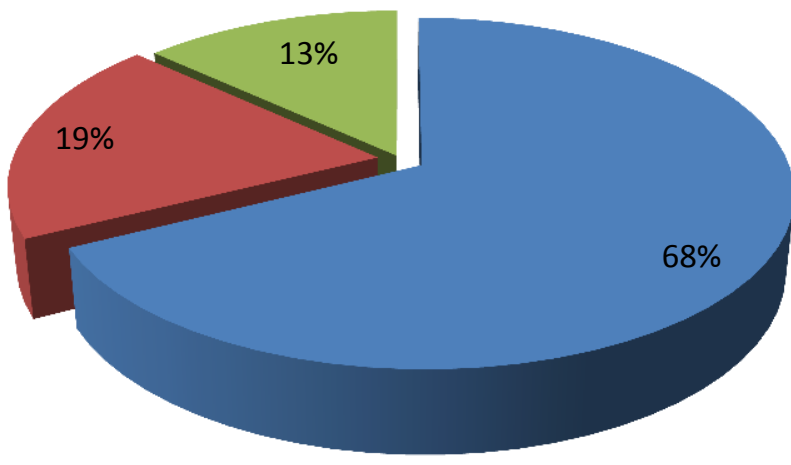

nigh moderate low

Figure (7): Levels of staff nurses according to overall work overload

Staff nurses' perception according to overall work instability

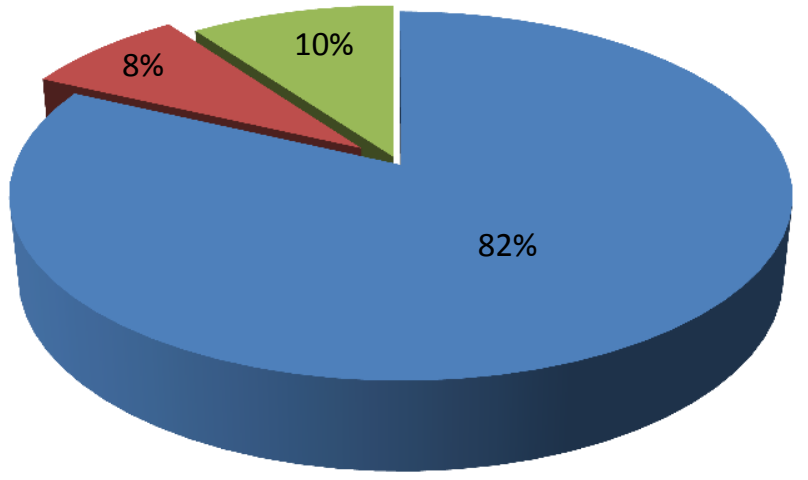

uigh moderate $\square$ low

Figure (8): Levels of staff nurses according to overall work instability 


\section{Tanta Scientific Nursing Journal}

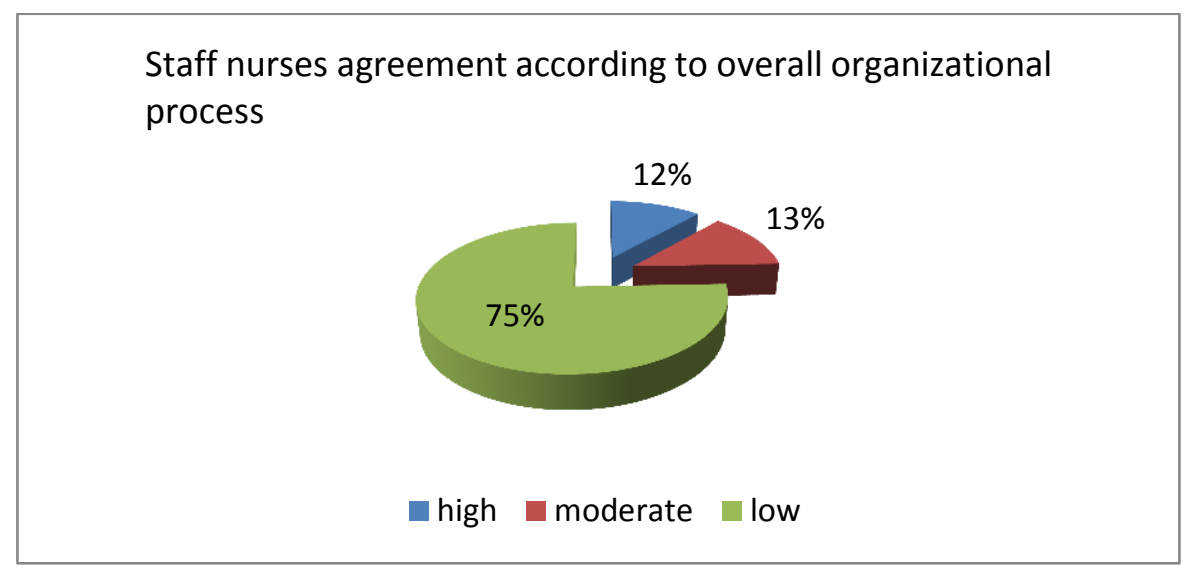

Figure (9): Levels of the staff nurses agreement according to overall organizational process

Table (2): Distribution of the staff nurses' opinion regarding to reporting of bullying

\begin{tabular}{|c|c|c|}
\hline Reporting of bullying items & No. & $\%$ \\
\hline \multicolumn{3}{|l|}{-Reporting of bullying in case of experienced it } \\
\hline No & 116 & 46.4 \\
\hline Yes & 134 & 53.6 \\
\hline \multicolumn{3}{|l|}{-Reporting of bullying in case of witnessed it } \\
\hline No & 132 & 52.8 \\
\hline Yes & 118 & 47.2 \\
\hline \multicolumn{3}{|l|}{ If yes: $(n=156)$} \\
\hline \multicolumn{3}{|l|}{\begin{tabular}{|l|}
-The reasons for not reporting the bully \\
\end{tabular}} \\
\hline - I did not know how to make a report & 88 & 35.2 \\
\hline - I did not think it is serious enough & 84 & 33.6 \\
\hline - $\quad$ I feared reprisal & 104 & 41.6 \\
\hline - $\quad$ I decided to move position instead & 107 & 42.8 \\
\hline - $\quad$ I did not think I could prove it & 91 & 36.4 \\
\hline - $\quad$ I would be labeled a troublemaker & 89 & 35.6 \\
\hline - $\quad$ Nothing would have been done & 57 & 22.8 \\
\hline - $\quad$ The process is too complicated & 97 & 38.8 \\
\hline - $\quad$ It would have affected my career & 104 & 41.6 \\
\hline \multicolumn{3}{|l|}{ The person that you make the report to } \\
\hline - $\quad$ Head nurse & 77 & 30.8 \\
\hline - $\quad$ Supervisor & 112 & 44.8 \\
\hline - $\quad$ Director & 64 & 25.6 \\
\hline - $\quad$ Administrator & 113 & 45.2 \\
\hline
\end{tabular}




\section{Tanta Scientific Nursing Journal}

Table (3): Distribution of staff nurses' opinion regarding to job consequences as a type of workplace bullying consequences

\begin{tabular}{|c|c|c|c|c|}
\hline \multirow{3}{*}{ Job consequences items } & \multicolumn{4}{|c|}{ Nurses' response } \\
\hline & \multicolumn{2}{|c|}{ Yes } & \multicolumn{2}{|c|}{ No } \\
\hline & No. & $\%$ & No. & $\%$ \\
\hline - I reported bullying, am no longer bullied & 161 & 64.4 & 89 & 35.6 \\
\hline - It was reported, but ignored & 135 & 54.0 & 115 & 46.0 \\
\hline - $\quad$ It was investigated, but nothing change & 165 & 66.0 & 85 & 34.0 \\
\hline - $\quad$ It was swept under the carpet & 154 & 61.6 & 96 & 38.4 \\
\hline - $\quad$ I was told I was weak and not coping & 186 & 74.4 & 64 & 25.6 \\
\hline - I was given counseling & 131 & 52.4 & 119 & 47.6 \\
\hline - $\quad$ I was moved, not the bully & 183 & 73.2 & 67 & 26.8 \\
\hline - $\quad$ I was asked to mediate with the bully & 168 & 67.2 & 82 & 32.8 \\
\hline - $\quad$ I applied for workers compensation & 210 & 84.0 & 40 & 16.0 \\
\hline - $\quad$ I have reduced my hours of work & 199 & 79.6 & 51 & 20.4 \\
\hline - $\quad$ I was not longer working in my chosen field & 190 & 76.0 & 60 & 24.0 \\
\hline - I resigned from the organization & 167 & 66.8 & 83 & 33.2 \\
\hline - $\quad$ I have used my sick leave to cope & 201 & 80.4 & 49 & 19.6 \\
\hline - $\quad$ I moved positions within the organization & 199 & 79.6 & 51 & 20.4 \\
\hline - I have been overlooked for promotion & 195 & 78.0 & 55 & 22.0 \\
\hline
\end{tabular}




\section{Tanta Scientific Nursing Journal}

Table (4): Distribution of staff nurses' opinion according to bullying health problems as a type of workplace consequences

\begin{tabular}{|c|c|c|c|c|}
\hline \multirow{3}{*}{ bullying health problems items } & \multicolumn{4}{|c|}{ Nurses response } \\
\hline & \multicolumn{2}{|c|}{ No } & \multicolumn{2}{|c|}{ Yes } \\
\hline & No. & $\%$ & No. & $\%$ \\
\hline - Fatigue and exhaustion & 62 & 24.8 & 188 & 75.2 \\
\hline - $\quad$ Hypertension & 134 & 53.6 & 116 & 46.4 \\
\hline - $\quad$ Depression & 118 & 47.2 & 132 & 52.8 \\
\hline - $\quad$ Memory loss & 137 & 54.8 & 113 & 45.2 \\
\hline - Headaches & 82 & 32.8 & 168 & 67.2 \\
\hline - $\quad$ Exacerbation of existing illness & 170 & 68.0 & 80 & 32.0 \\
\hline - $\quad$ Anxiety & 112 & 44.8 & 138 & 55.2 \\
\hline - $\quad$ Panic attacks & 189 & 75.6 & 61 & 24.4 \\
\hline - $\quad$ Change in weight & 157 & 62.8 & 93 & 37.2 \\
\hline - $\quad$ Sleeplessness & 98 & 39.2 & 152 & 60.8 \\
\hline - $\quad$ Gastric upset & 144 & 57.6 & 106 & 42.4 \\
\hline
\end{tabular}

\section{Staff nurses' perception of overall work engagement}

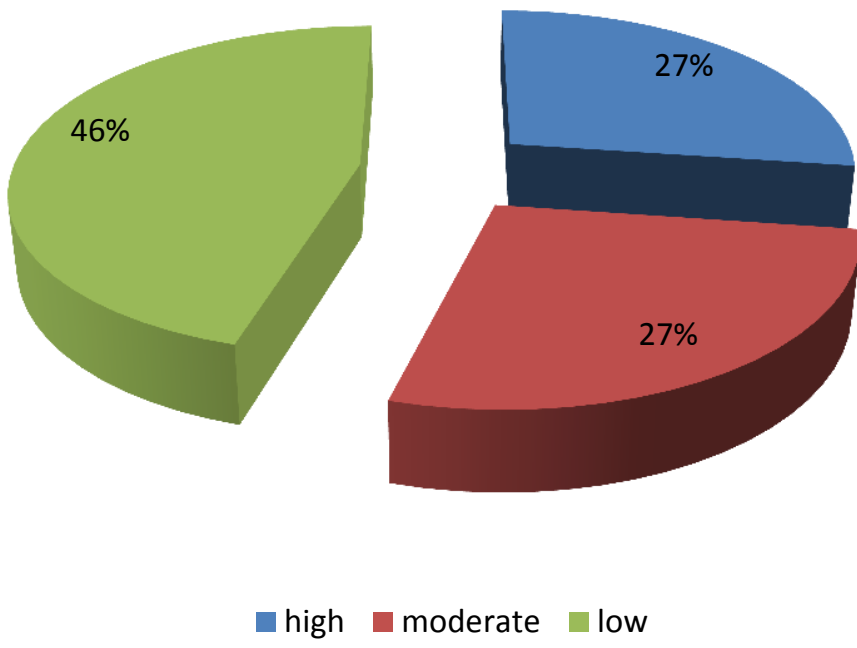

Figure (10): Levels of the staff nurses' perception of overall work engagement 


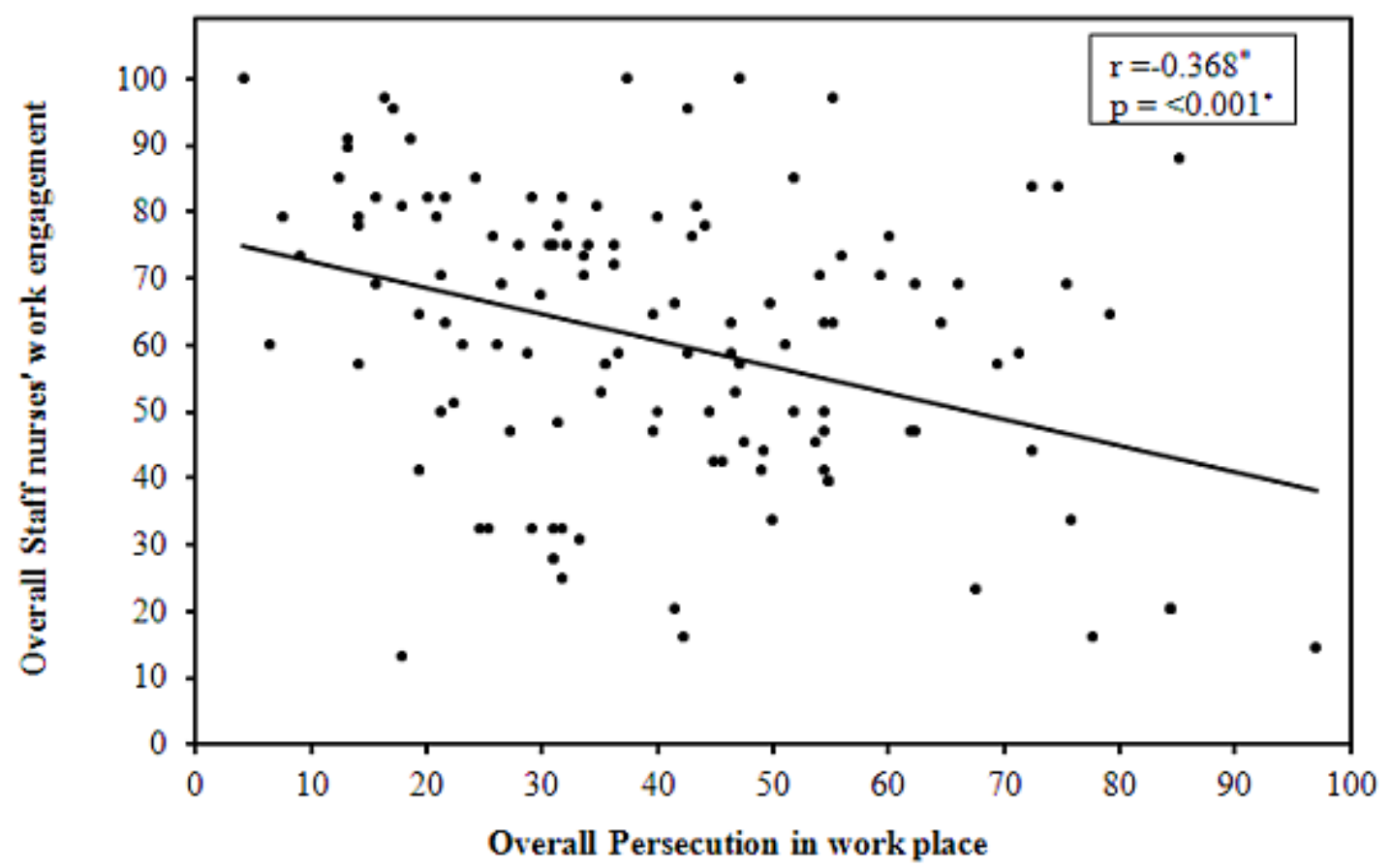

Figure (11): Correlation between workplace bullying with staff nurses' work engagement 


\section{Tanta Scientific Nursing Journal}

\section{Discussion}

Today, there is an increasing evidence of nursing staff being exposed to violent behavior as workplace bullying. Bullying is a serious issue affecting the nursing profession, as bullying present in all work environments and nurses are on the frontline of the health care and have the closest contact with patients and their relatives. Workplace bullying has serious negative consequences that may extend beyond individual nurses to an entire health care organization, such as experiencing stress, frustration, physical and psychological disorders, poor engagement and leave a particular place of employment ${ }^{(4,10)}$.

The result of the present study revealed that more than half of staff nurses experienced bullying at workplace which should be a cause for concern as it brings special attention to bullying the health care.

This result is congruent with Trepanier et al., (2016) (20), and Al-Wehedy et al., (2012) ${ }^{(21)}$ they reported that the majority of nurses were exposed to workplace bullying. Moreover, Abbas et al., (2010) (22) revealed that more than half of nurses' were exposed to violence during their work. In addition, Kwok et al., (2006) ${ }^{(23)}$ reported that bullying had been experienced by nurses in a percent of $76 \%$. On contrary this result is disagreed with Karatza (2016) ${ }^{(24)}$ who showed that the majority of the respondents did not face bullying incidents at their workplace within a year. Also, Budin et al., (2013) (24), found that a majority of nurses perceived no exposure to bullying.

The present study revealed that the majority of staff nurses had high level of overall bullying. The result of the present study agreed with Nwaneri et al., (2016) (25) who found workplace bullying among nurses is reported to be high. Also, this finding is consistent with Etienne, $\mathbf{2 0 1 4}^{(126)}$, Berry et al., 2012 ${ }^{(27)}$, found higher levels of bullying among samples of nurses who work in U.S. hospitals.

Regarding bully person, the present study revealed that more than one-third of staff nurses reported that bullying was related to head nurses. In the same line with the present result was Bardakci, (2016) (44) who reported that most of the bullying behaviors were perpetrated by head nurses. Also, Trepanier et al., (2013), ${ }^{(45)}$ Cevicakyil et al., (2012) ${ }^{(39)}$, and Efe and Ayaz's(2010) ${ }^{(43)}$ found that nurses are 


\section{Tanta Scientific Nursing Journal}

subjected to bullying behaviors perpetrated by head nurses. While, this result disagreed with Ebrahim, (2018) ${ }^{(28)}$ who reported that the source of bullying behavior was nurses and physician are the most frequent sources of bullying behaviors.

In relation to the professional threat as a type of bullying, the present study revealed that majority of staff nurses had high level of overall professional threats. This study finding may be due to the un ability of staff nurses to deal with bullies, increased workload, shortage of hospital staff, inability to take uninterrupted breaks, inadequate staffing ratios and limited supplies. This study result is disagreed with Fountain (2016) ${ }^{(15)}$, who found that the majority of nurses perceived no exposure to erosion of professional competence and reputation.

Regarding to personal threat as a type of bullying, the present study revealed that majority of staff nurses had high level of overall personal threat. This result may be due to the most of the nurses felt that expression of such acts threatened their dignity so avoid working with the bully, overwhelming workloads, excessively long shifts, lots of responsibilities and too much burden on nurses. This finding is inconsistent with Budin et al., (2013) ${ }^{(24)}$, who found lower levels of personal attacks of bullying among early career nurses.

Concerning work isolation as a type of bullying, the present study revealed that nearly three-quarters of staff nurses had high level of overall work isolation. This study result may be due to denial of due process and use of earned benefits, bad communication and unfair economic restrictions. This result agreed with Berry et al., (2012) ${ }^{(27)}$ who found higher levels of attack through work roles and tasks among samples of nurses who work in U.S. hospitals

In relation to work overload as a type of bullying, the result of the present study revealed that more than half of staff nurses had high level of overall work overload. This study results may be due to the perpetrator is often senior position and the subsequent complaint may be seen as simply jealousy, resulting in repercussions and a certain amount of pressure, and unfair work assignment. The result of the present study disagreed with Wilson et al., (2011) (34) who reported that $30.5 \%$ of nurse participants in the study reported moderate or substantial exposure to work overload in the workplace. 


\section{Tanta Scientific Nursing Journal}

Regarding to work instability as a type of bullying, the result of the present study showed that majority of staff nurses had high level of overall work instability. This study result may be due to those nurses still believed that bully had undervalued their efforts and participation, lack of appreciation and work opportunities and a misunderstanding of staff rights and responsibilities. The result of the present study was disagreed with Mahmoud, (2019) ${ }^{(32)}$ who found that the participants had moderate level of work instability

In relation to organizational system with bullying treating, the result of the present study revealed that three-quarter of staff nurses had low agreement level regarding overall organizational processes. The result of the present study was contraindicated with Mahmoud, (2019) ${ }^{(32)}$ who showed that more than half of the staff nurses strongly disagreed about bullies summoned them to meet without notice and intimidated. Also, nearly one third of them disagreed about the bullies make gang on them. Nearly half of them not sure about the records from meetings are falsified and using the restructure to force out those not supportive of bullies
In relation to reporting bullying by staff nurses, the result of the present study revealed that around half of staff nurses reported the bullying in case of experience it. This result was consistent with Mahmoud, (2019) ${ }^{(32)}$ who revealed that more than half of the staff nurses reported the bullying. Opposite to the present finding Bardakci, (2016) ${ }^{(44)}$ who reported that the nurses reacted to bullying behaviors mostly by keeping silent and sharing the issue with friends and family. Regarding to the health problems of bullying on staff nurses, the results of the present study revealed that over threequarters of the bullied nurses complained from fatigue and exhaustion. Also, more than half of them complained from headaches, sleeplessness, anxiety, and depression. The finding of the present study was congruent with Ekici \& Beder, (2014) ${ }^{(41)}$ who found that the nurses who were suffering from the effect of bullying, usually experience sever psychiatric, psychosomatic and psychosocial problems. Stanley, (2014) ${ }^{(35)}$, and Dewet, (2010) ${ }^{(36)}$ found that the impact of workplace bullying participants is significant, 53\% of them experienced physical and emotional 


\section{Tanta Scientific Nursing Journal}

consequences including loss of sleep, loss of appetite, anxiety, depression and compromised self-confidence.

Concerning job consequences of bullying reporting, the result of the present study revealed that the majority of staff nurses reported the bullying, applied for worker compensation, used their sick leave to cope, reduced their hours of work, and moved positions within the organization. This result in the same line with Nwaneri et al., (2016) ${ }^{(25)}$ who reported that more than half of staff nurses left their job within six months due to workplace bullying. Also, Chesler, (2014) (13) reported that the nurses changed jobs to avoid the bullies.

The result of the present study revealed that the majority of staff nurses had high level of workplace bullying and more than two-fifths of staff nurses had low level perception of overall work engagement. The result of present study was agreed with Fountain (2016) ${ }^{(15)}$ who revealed that staff nurses, those nurses who work on medical/surgical units and those who work in non-acute hospital settings had lower levels of work engagement. Conversely, the result of present study was disagreed with, Badran (2019) ${ }^{(37)}$ who revealed that less than two-thirds of the sample had moderate work engagement level.

The result of the present study revealed that, there was statistically negative significant correlation between nurses perceived bullying and their engagement. This result may be due to the nurses had poor of ability to deal with workplace bullying and the nurses are unable to function at their full capacity when bullying continue in the workplace.

\section{Conclusion:}

The study result concluded that, majority of staff nurses had high level of workplace bullying. Specifically, the highest mean scores was related to professional threat, followed by work overload and the lowest mean scores was related to work instability and more than half of staff nurses reported the bullying, around one-third of staff nurses' were reported that the source of their bullying were head nurse. In addition, more than two-fifths of the staff nurses had low level of work engagement and dedication was perceived by staff nurse as being the highest mean score. There was statistically significant correlation between nurses' bullying and their work engagement. These findings answer all research questions. 


\section{Recommendation:}

\section{Nursing level}

- Nurses at all levels, including administrators and staff nurses, need to be informed to report bullying.

- Conduct training program for staff nurses about bullying and different strategies to deal with it, including verbal, nonverbal and writing down techniques.

\section{- Organizational level}

- Nursing administrators need to develop policies to prevent bullying and antibullying reporting tools and mechanisms that allow nurses' who exposed to workplace bullying to report incidents of bullying .

\section{Educational level}

-Nursing administration curriculum need to include topics about bullying behaviors .

\section{Further researches}

-Need to be conducted to identify the effective strategies to eliminate bullying behaviors .

-Assess the impact of workplace bullying on the organizational outcomes and patient outcomes.

\section{References:}

1. Yamada D, Duffy $M, \&$ Berry $P$. Workplace Bullying and Mobbing: Definitions, Terms, and When They
Matter. Workplace Bullying and Mobbing in the United States. 2018; 2(1): 2-6.

2. Zych I, Ortega-Ruix R, \& Del Rey R. Systematic review of theoretical studies on bullying and cyber bullying: facts, knowledge, prevention, and intervention. Aggression and Violent Behavior. 2015; 23(4): 1-21.

3. D'Ambra, \& Andrews D. Incivility, retention and new graduate nurses: an integrated review of the literature. Journal of nursing management 2014; 22(6): 735742.

4. Einarsen $\mathbf{S}, \boldsymbol{\&}$ Hoel $\mathbf{H}$, Zapf $D, \&$ cooper C. The concept of Bullying and Harassment at Work: The European

Tradition. 2011; $2^{\text {nd }}$ Ed, CRC press Taylor \& Francis Group, (1): 6-17.

5. Ramsay C, Torth A, \& Branch $\mathbf{S}$. Workplace bullying: A group processes framework. Journal of Occupational and Organizational Psychology. 2010; 84(4): 799-816.

6. Workplace Bullying Institute (WBI). Workplace Bullying Survey. USA. 2014; 31(2): 43.

7. Namie G, \& Namie R. Bullying is Domestic Violence at Work: The Abuser is on The Payroll! (Wiley and Son). 2011;44(5):18-23.

8. Linsley $\mathbf{P}$. Violence and Aggression in The Workplace: A practical Guide for All Healthcare Staff. CRC Press.2016; 72(2): 101.

9. Ariza-Montes A., Leal-Rodríguez A. L., \& Leal-Millán A. G. A comparative study of workplace bullying among public and private employees in Europe. Journal of Occupational and Environmental Cheung P, \& Yip P F. Workplace violence towards nurses in Hong Kong: prevalence 
and correlates. BMC Public

Health.2017;17(1): 1-10.

10. Bradbury, J., \& Hutchinson, M. Workplace bullying: Modelling construct validity in an Australian public sector workforce. Journal of Empirical Studies. 2015; 2(1): $1-16$. doi:10.18488/journal.66/2015.2.1/66.1.1.1 6.

11. Antoinette Ettebargagliotti L, Work engagement in nursing: a concept analysis. Journal of Advanced Nursing.2012; 68: (6), 1414-1428. Doi: 10.1111/ j.13652648.2011.05859.x.2012.

12. Bakker A, \& Leiter M., Where to go from here: Integration and future research on work engagement. In A. B. Bakker \& M. P. Leiter (Eds.), Work engagement: a handbook of essential theory and research. 2010; 181-196. New York, NY, US: Psychology Press.

13. Bakker, A., \& Schaufeli, W., Defining and measuring work engagement: Bringing clarity to the concept. In Work engagement: a handbook of essential theory and research (Bakker, A. B. and Leiter, M. P. (eds.) Psychology Press Hove. 2010; 42(2): 10-24.

14. Bakker A, Demerouti E, \& Sanz-Vergel A, Burnout and Work Engagement: The JD-R Approach. Annual Review of Organizational Psychology and Organizational Behavior. 2014; 1(0): 21 26.

15. Burke G, \& El-kot R. Work engagement among managers and professionals in Egypt Potential antecedents and consequences. African Journal of Economic and Management Studies.2010;1(1):42-60.

16. Medicine. 2015; 57(6): 695-700.

17. Park J, \& Ono M. Effects of workplace bullying on work engagement and health: the mediating roles of job insecurity. The International Journal of Human Resource Management. 2016; 28(22):3202-3225.

18. Fasoli D. The culture of nursing engagement: A historical perspective. Nursing Administration Quarterly. 2010; 34(1):18-29.

19. Çevik-Akyil R, Tan M, Saritaş $\mathbf{S}, \&$ Altuntaş S. Levels of mobbing perception among nurses in Eastern Turkey. International Nursing Review. 2012; 59(3): 402- 408.

20. Clendon j, \& Walker L. Being young: A qualitative study of younger nurses' experiences in the workplace. International Nursing Review. 2012; 59(4):555-61 .

21. Efe S, \& Ayaz S. Mobbing against nurses in the workplace in Turkey. International Nursing Review. 2010; 57(6):328-334

22. Cooper-Thomas H., Gardner D., O'Driscoll M., Catley T., Bentley T., \& Trenberth, L. Neutralizing Workplace Bullying: The buffering effects of contextual factors. Journal of Management Psychology. 2013; 28(4):384-407. doi:10.1108/JMP-12-2012-0399

23. Ekici D, \& Beder A. The effects of workplace bullying on physicians and nurses. Research paper. Australian Journal of Advanced Nursing. 2014; 31(4): 24-44.

24. Bardakçi E, \& Günüşen, N. Influence of workplace bullying on Turkish nurses' psychological distress and nurses' reactions to bullying. Journal of Transcultural Nursing, 2016; 27(2), 166171.

25. Fapohunda T. Managing workplace bullying. Journal of Human Resource Management. 2013; 1(3):39-47.

26. Karatza C, Zyga S, Tzlaferi S, \& prezerakos p. Workplace Bullying and 
General Health Status Among the Nursing Staff of Greek Public Hospitals. Annals of General Psychiatry. 2016.

27. Chesler J C. The Impact of Workplace Bullying on Employee Morale, Job Satisfaction and Productivity within Non Profit Organizations. Doctoral Dissertation, Capella University. 2014.

28. Fountain M. Relationships among Work Engagement, Drivers of Engagement, and Bullying Acts in Registered Nurses Working in Hospital Settings. Doctorate Dissertation. The Graduate School-Newark Rutgers, the State University of New Jersey. 2016.

29. El-sayed, A. Workplace Bullying and absenteeism rate among staff nurses at Mansoura University Hospital. Unpublished Master Thesis .Faculty Of Nursing, Mansoura University.2015.

30. Hutchinson M. A new model of bullying in the nursing workplace organizational characteristics as critical antecedents. Advances in Nursing Science. 2008; 31:E60-E71.

31. Schaufeli, W. The measurement of work engagement, Research methods in occupational health psychology: Measurement, design, and data analysis. New York, NY: Rutledge. 2012; 43(1):138-153.

32. Trêpanier S, Fernet $\mathbf{C}$, Austin $\mathbf{S}, \&$ Boudrias V. Work environment antecedents of bullying: A review and integrative model applied to registered nurses. International Journal of Nursing Studies. 2016; 55: 85-97.

33. Al-Wehedy A, El-sayed R. \& Abd Elmouty $S$. violence against nurses working at an Emergency Hospital, Egypt. Poster. In $3^{\text {rd }}$ international conference on violence in health sector. 2012.
34. Abbas M, Fiala L, Abdel Rahman A, \&Fahim E. Epidemiology of workplace violence against nursing staffin Ismailia Governorate, Egypt. J Egypt Public Health Assoc., 2010; 85 (1-2), 29-43.

35. Kwok R, Law Y, Cheung M, Fung V, \& et al. Prevalence of workplace violence against nurses in Hong Kong. Hong Kong Med. 2006; 12 (1): 6-9.

36. Budin W. C., Brewer C. S., Chao Y-Y. \&, Kovner C. Verbal abuse from nurse colleagues and work environment of early career Registered Nurses. Journal of Nursing Scholarship. 2013; 45(3), 308316. doi: 10.1111/jnu.12033.

37. Nwaneri A. C, Onoka A. C, \& Onoka C. A. workplace bullying among nurses working in tertiary hospitals in Enugu, Southeast Nigeria: Implication for health workers and job performance. Journal of Nursing Education and Practice. 2016; 7 (2): 68-79.

38. Etienne E. Exploring workplace bullying in nursing. Workplace Health Safety. 2014; 62(1):6-11.

39. Berry P. A., Gillespie G. L., Gates D., \& Schafer J. Novice nurse productivity after workplace bullying. Journal of Nursing Scholarship. 2012; 44(1): 80-87. doi: 10.1111/j.1547-5069.2011.01436.x.

40. Ebrahim R, The Relationship between Bullying, Achievement Factors, and SelfEsteem among Nursing Students .International Journal of Novel Research in Health care and Nursing. 2018; 5(3): 476489 Available

at: www.noveltyjournals.com.

41. Mahmoud A. Effect of Workplace Bullying on Nurses Job Performance, Unpublished Master Thesis. Faculty of Nursing. Benha University. 2019.

42. Stanley, K. Disruptive Behaviors in Nursing Practice and Education, Visionary 


\section{Tanta Scientific Nursing Journal}

Leadership for Psychiatric Mental Health Nurses around the World. Journal of International Society of Psychiatric Mental Health Nurses. 2014; 2(3):1-12.

43. De Wet, C. The reasons and the impact of principal-on-teacher bullying on the victims' private and professional lives, Teaching and Teacher Education. 2010; 26(7):1450-1459.

44. Badran F. Person Organizational Fit and Work Engagement among Head Nurses, International Journal of Novel Research in Healthcare and Nursing. 2019; 6(1): 921932. Available at: www.noveltyjournals.com.
45. Elena Fiabane, Ines Giorgi, Cinzia Sguazzin and Piergiorgio Argentero. Work engagement and occupational stress in nurses and other healthcare workers: the role of organizational and personal factors, Journal of Clinical Nursing. 2014; 52(5): 484-493. 